\title{
Evaluation of the Hydration Characteristics and Anti-Washout Resistance of Non-Dispersible Underwater Concrete with Nano-SiO ${ }_{2}$ and $\mathrm{MgO}$
}

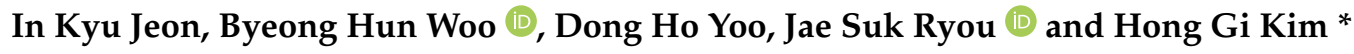

check for updates

Citation: Jeon, I.K.; Woo, B.H.; Yoo, D.H.; Ryou, J.S.; Kim, H.G. Evaluation of the Hydration Characteristics and Anti-Washout Resistance of Non-Dispersible Underwater Concrete with Nano- $\mathrm{SiO}_{2}$ and $\mathrm{MgO}$. Materials 2021, 14, 1328. https://doi.org/10.3390/ ma14061328

Academic Editor: Hubert Rahier

Received: 17 February 2021

Accepted: 8 March 2021

Published: 10 March 2021

Publisher's Note: MDPI stays neutral with regard to jurisdictional claims in published maps and institutional affiliations.

Copyright: (c) 2021 by the authors. Licensee MDPI, Basel, Switzerland. This article is an open access article distributed under the terms and conditions of the Creative Commons Attribution (CC BY) license (https:// creativecommons.org/licenses/by/ $4.0 /)$.
Civil and Environmental Engineering Department, Hanyang University, Jaesung Civil Engineering Building, 222 Wangsimni-ro, Seongdong Gu, Seoul 04763, Korea; supermacy94@daum.net (I.K.J.); dimon123@hanyang.ac.kr (B.H.W.); dongho3461@naver.com (D.H.Y.); jsryou@hanyang.ac.kr (J.S.R.)

* Correspondence: dmkg1404@hanyang.ac.kr; Tel.: +82-2-2220-4323

Abstract: In this paper, the effect of nano- $\mathrm{SiO}_{2}$ (NS) and $\mathrm{MgO}$ on the hydration characteristics and anti-washout resistance of non-dispersible underwater concrete (UWC) was evaluated. A slump flow test, a viscosity test, and setting time measurement were conducted to identify the impacts of NS and $\mathrm{MgO}$ on the rheological properties of UWC. The $\mathrm{pH}$ and turbidity were measured to investigate the anti-washout performance of UWC mixes. To analyze the hydration characteristics and mechanical properties, hydration heat analysis, a compressive strength test, and thermogravimetric analyses were conducted. The experimental results showed that the fine particles of $\mathrm{NS}$ and $\mathrm{MgO}$ reduced slump flow, increased viscosity, and enhanced the anti-washout resistance of UWC. In addition, both $\mathrm{NS}$ and $\mathrm{MgO}$ shortened the initial and final setting times, and the replacement of $\mathrm{MgO}$ specimens slightly prolonged the setting time. NS accelerated the peak time and increased the peak temperature, and $\mathrm{MgO}$ delayed the hydration process and reduced the temperature due to the formation of brucite. The compressive results showed that NS improved the compressive strength of the UWC, and $\mathrm{MgO}$ slightly decreased the strength. The addition of NS also resulted in the formation of extra C-S-H, and the replacement of $\mathrm{MgO}$ caused the generation of a hydrotalcite phase.

Keywords: underwater concrete; anti-washout; hydration; nano- $\mathrm{SiO}_{2} ; \mathrm{MgO}$

\section{Introduction}

As bridges continue to age, experts have been increasingly concerned about their structural safety, and suggest strengthening procedures. However, structures located underwater are more difficult to strengthen than superstructures. The existing strengthening methods [1-6] for substructures are costly, traffic-disrupting, and have a long construction time. To deal with these weak points of conventional strengthening methods, the FRP underwater strengthening method [7], the jacket strengthening method [8], and the precast concrete segment assembly method [9] have been proposed. Underwater concrete (UWC) is commonly used in these methods, and its performance is important in determining strengthening efficiency $[10,11]$.

UWC is generally produced using viscosity-modified admixtures (VMAs) and antiwashout admixtures (AWAs) to fabricate viscous concrete mixes [12]. It is directly poured into water, and washout resistance is a significant factor that determines its strength, durability, and workability. In underground engineering, UWC with anti-washout characteristics is used due to its excellent viscosity, low dispersibility, and low water pollution potential [13]. As UWC is based on self-compacting concrete, its rheological properties must be adequately maintained to ensure higher washout resistance.

Several attempts have been made to control the rheological properties and washout resistance of UWC. Park et al. [14] studied the various contents of AWA and its superplasticizer, and found that the optimum content of UWC is 1\% AWA and 5.5\% superplasticizer. 
Kumar et al. [15] mentioned that a combination of AWAs can postpone the setting time and strengthen the rheological properties of UWC. Khayat et al. [16] achieved higher anti-washout resistance using fly ash and silica fume as viscosity-enhancing agents. In addition, Grzeszczyk et al. [17] used a nanomaterial to enhance the anti-washout resistance of UWC. Sonebi et al. [18] used $8 \%$ silica fume and $20 \%$ cement binder instead of fly ash to control the workability and stability of UWC, which also decreased the segregation coefficient, washout loss, and surface settlement. Kojouri et al. [19] used lime powder as a mineral additive in UWC and found that it enhanced washout resistance, workability, the acceleration of the hydration reaction, and compressive strength.

Nano- $\mathrm{SiO}_{2}$ (NS) is the common name for nano-sized silica particles with a diameter between $5 \mathrm{~nm}$ and $100 \mathrm{~nm}$. NS particles are about 1000 times smaller than OPC particles [20]. Previous studies [21,22] found that NS can strengthen the cement matrix due to its smaller particles, high pozzolanic activity, and ability to form dense and compact microstructures. Because of these properties of NS, many studies focus on enhancing the mechanical performance and durability of cement composites with different percentages of NS [23-28]. However, only a few studies [17] of NS have been used to control the washout resistance of UWC. Therefore, further specific investigations and analyses of the fluidity and anti-washout resistance of UWC with NS are needed.

Magnesium oxide $(\mathrm{MgO})$ is widely used in concrete manufacturing. Previous studies have demonstrated that the hydration and expansion characteristics of $\mathrm{MgO}$ positively affected concrete by reducing the hydration heat, decreasing the shrinkage, and changing the porosity and pore size distribution [29-32]. As the anti-washout resistance of concrete depends on the fine fraction of its binder material, various very fine mineral additives have been suggested to control the anti-washout properties of UWC [17]. Fly ash, silica fume, and ground granulated blast furnace slag have been generally used as mineral additives in UWC mixes $[33,34]$. Studies have shown that the incorporation of mineral admixtures in UWC is sought around the world to produce high-quality non-dispersible UWC. Although much attention has been given to fly ash, silica fume, and granulated blast furnace slag, there are few data available on the effects of $\mathrm{NS}$ and $\mathrm{MgO}$ on the anti-washout resistance of UWC.

In summary, this study investigated the effects of $\mathrm{NS}$ and $\mathrm{MgO}$ as mineral admixtures on the workability, washout properties, strength development, and hydration process of UWC. A slump flow test and a viscosity test were conducted to analyze these effects on the workability of UWC; the $\mathrm{pH}$ and turbidity measurement tested the anti-washout resistance of UWC; the setting time and isothermal conduction calorimetry were used to determine the hydration characteristics of UWC; and a compressive strength test measured the mechanical property of UWC.

\section{Experimental Details}

\subsection{Materials}

Ordinary Portland Cement (OPC) obtained from A company (Seoul, Korea) that complies with ASTM C-150 [35] was used as the primary binding material. Specifically, fine and coarse aggregates with maximum sizes of $5 \mathrm{~mm}$ and $25 \mathrm{~mm}$, respectively, were used. The fine aggregate had a fineness of modulus (F.M) of 2.7 and a water absorption capacity of $1.05 \%$, and the coarse aggregate had a specific gravity of 2.63, an F.M. of 7.01, an abrasion of $45 \%$, and a water absorption capacity of $1.02 \%$. To achieve the needed fluidity of UWC, a poly-carboxylate-based superplasticizer from E company in Seoul (SP) was used. Commercially available hydroxypropyl-methylcellulose (HPMC)-based anti-washout admixture (AWA) from a local E company in Seoul was used to produce non-dispersible UWC mixes. Magnesium oxide ( $\mathrm{MgO})$ with a purity of $80.1 \%$, especially light burned magnesia (LBM), sourced from R company in Gwangyang, Korea was used as the binder replacement material. The gradation curves for the OPC and $\mathrm{MgO}$ used are shown in Figure 1. The gradation curves indicated that the $\mathrm{MgO}$ particles have a smaller 
size compared to OPC. Nano-SiO 2 (NS) powder with a purity of $99.5 \%$ and average particle sizes of approximately $20-40 \mathrm{~nm}$ was used as an additional binder material.

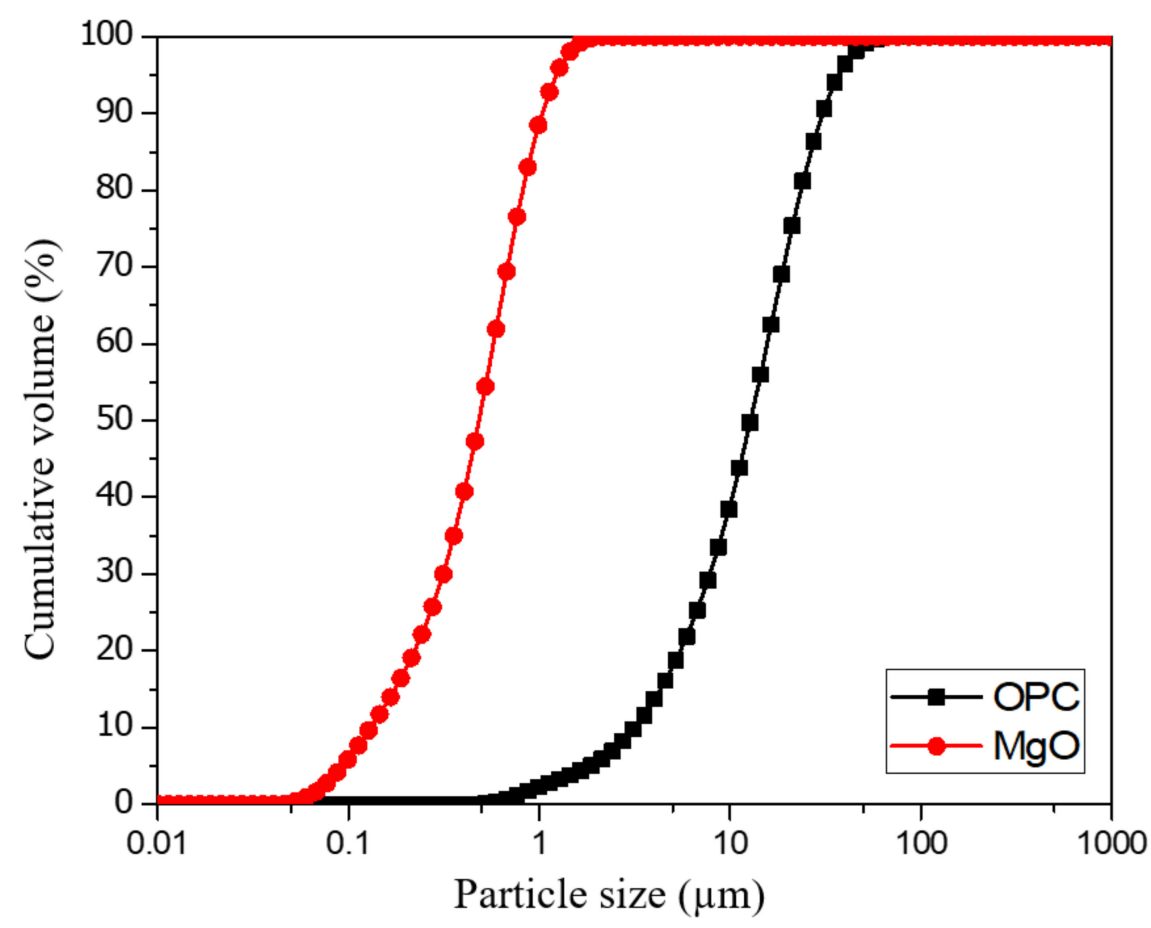

Figure 1. Particle size distributions of Ordinary Portland Cement (OPC) and magnesium oxide $(\mathrm{MgO})$.

\subsection{Mix Proportions and Fabrication of Specimens}

Five mix proportions of non-dispersible UWC and control concrete mixtures were prepared. Table 1 shows the mix proportions of all the concrete mixes produced in this study, which were classified into two types. The NS series denotes the sample with NS powder, and the $\mathrm{M}$-series represents the samples with $\mathrm{MgO}$. The numbers after $\mathrm{NS}$ and $\mathrm{M}$ indicate the dosage: $0 \%, 5 \%$, and $10 \%$ of the weight of OPC was sequentially replaced with $\mathrm{MgO}$, and NS powder was sequentially added at $0 \%, 1 \%$, and $2 \%$ of the OPC weight. A water binder (Sum of OPC and $\mathrm{MgO}$ ) ratio of 0.45 , a superplasticizer content of $2 \%$ of the weight of the binder, and an AWA content of $0.5 \%$ of the weight of the binder were used, followed by a standard mix of $25 \mathrm{MPa}$ target strength UWC obtained from a local concrete company. Concrete cylinders with dimensions of $\Phi 100 \mathrm{~mm} \times 200 \mathrm{~mm}$ were prepared following ASTM C 31 [36]. The casting method of the anti-washout UWC was adopted from previous study [37]. The UWC specimens were demolded after they were cured for $24 \mathrm{~h}$ and placed in a water curing condition until the set curing age was reached.

Table 1. Concrete mix proportions.

\begin{tabular}{|c|c|c|c|c|c|c|c|c|}
\hline $\begin{array}{l}\text { Concrete } \\
\text { Mix }\end{array}$ & $\begin{array}{c}\text { OPC } \\
\left(\mathrm{kg} / \mathrm{m}^{3}\right)\end{array}$ & $\underset{\left(\mathrm{kg} / \mathrm{m}^{3}\right)}{\mathrm{MgO}}$ & $\begin{array}{c}\text { Nano-SiO } \\
\left(\mathrm{kg} / \mathrm{m}^{3}\right)\end{array}$ & $\begin{array}{c}\text { Fine } \\
\text { Aggregate } \\
\left(\mathrm{kg} / \mathrm{m}^{3}\right)\end{array}$ & $\begin{array}{c}\text { Coarse } \\
\text { Aggregate } \\
\left(\mathbf{k g} / \mathrm{m}^{3}\right)\end{array}$ & $\begin{array}{c}\text { AWA } \\
\left(\mathrm{kg} / \mathrm{m}^{3}\right)\end{array}$ & $\begin{array}{c}\mathrm{SP} \\
\left(\mathrm{kg} / \mathrm{m}^{3}\right)\end{array}$ & $\begin{array}{c}W \\
\left(\mathrm{~kg} / \mathrm{m}^{3}\right)\end{array}$ \\
\hline Control & \multirow{3}{*}{440} & \multirow{3}{*}{-} & - & \multirow{5}{*}{708} & \multirow{5}{*}{889} & \multirow{5}{*}{2.4} & \multirow{5}{*}{7.92} & \multirow{5}{*}{198} \\
\hline NS1 & & & 4.4 & & & & & \\
\hline NS2 & & & 8.8 & & & & & \\
\hline M5 & 418 & 22 & \multirow{2}{*}{-} & & & & & \\
\hline M10 & 396 & 44 & & & & & & \\
\hline
\end{tabular}




\subsection{Experiment Methods}

The concrete mixes were prepared with a laboratory-scale concrete mixer (MR500, Inter, Korea). The fresh properties of the UWC mixes were determined by testing their workability. The slump test was conducted according to ASTM C 143 [38]. The viscosity values of the UWC mixes with $\mathrm{NS}$ and $\mathrm{MgO}$ were assessed with a rheometer (Rheometer R/S Plus, Brookfield, WI, USA). To observe the setting time of the fresh UWC mixes, paste samples were obtained after mixing the UWC concrete, and the initial and final setting times were investigated using Vicat needles [39,40] according to ASTM C 191 [41].

To measure the anti-washout resistance of the UWC mixes, the $\mathrm{pH}$ and turbidity measurements preceded via a method used in a previous study [42]. First, $500 \mathrm{~g}$ of UWC was slowly poured into a beaker. After $3 \mathrm{~min}, 100 \mathrm{~mL}$ of water from the top surface of the beaker was extracted using a pipette, its $\mathrm{pH}$ was immediately evaluated with a $\mathrm{pH}$ meter, and its turbidity was measured in accordance with EN ISO 7027 [43] using a turbidity machine (TB 300IR, Lovibond, Amesbury, UK).

To evaluate the mechanical properties of UWC concrete mixes, the compressive strength of the concrete cylinders with dimensions of $\Phi 100 \mathrm{~mm} \times 200 \mathrm{~mm}$ at 7 and 28 days of curing was measured using a universal testing machine (UTM, Shimadzu, CCM-200A; Shimadzu Corporation, Kyoto, Japan) and following ASTM C39 [44]. Three replicates were used for each mix.

Isothermal calorimetry is a convenient means of examining the hydration characteristic of cementitious materials at early ages. The heat evolution was investigated using a semiadiabatic calorimeter, as in a previous study [45]. The specimens were placed in the calorimeter $2 \mathrm{~min}$ after the water and binder were mixed. The temperature change was measured every $3 \mathrm{~min}$ for $48 \mathrm{~h}$.

The hydration product of the UWC concrete specimens at later ages was measured via thermogravimetric analysis (TGA). The powder samples were obtained from pieces of the concrete specimens used for the compressive strength test. A thermogravimetric analyzer (TGA7 PERKIN ELMER, TA Instruments, New Castle, DE, USA) was used for TGA analysis in an $\mathrm{N}_{2}$ environment at a heating rate of $10 \mathrm{~K} / \mathrm{min}$ within a temperature range of 2 to $1000^{\circ} \mathrm{C}$.

\section{Results and Discussion}

\subsection{Slump Flow Test}

To evaluate the effects of NS and $\mathrm{MgO}$ on the workability of UWC concrete mixes, a slump flow test was conducted, as shown in Figure 2. The slump flow decreased with the addition of NS and its replacement with MgO. For example, slump values of $610 \mathrm{~mm}$, $601 \mathrm{~mm}$ and $574 \mathrm{~mm}$ were measured for the control, NS1, and NS2 concrete mixes, respectively, mainly due to the large specific surface area of the NS powder. The fine particles of NS in the cement matrix had the strongest effect on the total water demand of the concrete mixes [46]. Therefore, the finer the particle powder added, the less workable the UWC. In addition, the incorporation of $\mathrm{MgO}$ in the UWC concrete mixes reduced the slump flow value. For instance, slump flow values of $610 \mathrm{~mm}, 598 \mathrm{~mm}$, and $562 \mathrm{~mm}$ were measured for the control, M5, and M10 specimens, respectively. The decrease in fluidity with MgO was similar to the results of a previous study [47]. Finer $\mathrm{MgO}$ particles enhanced the cohesiveness of the cement paste, which reduced the fluidity. Furthermore, Zhang et al. [47] reported that the incorporation of reactive $\mathrm{MgO}$ decreased the workability of a cement composite, which increased its water demand to achieve a similar flow value.

\subsection{Viscosity Test}

Figure 3 shows the rheological properties of the UWC mixes with different amounts of NS and $\mathrm{MgO}$. Figure 3a shows the relationship between viscosity and shear rate, and Figure $3 \mathrm{~b}$ shows the shear stress versus shear rate flow curves for the UWC mixes. Figure $3 \mathrm{a}$ illustrates that the enhancement of the shear rate decreased the viscosity. The addition of NS and replacement OPC with $\mathrm{MgO}$ increased the viscosity compared to that of the 
control specimens. Among the five UWC mixes, that to which $2 \%$ NS was added showed significant viscosity enhancement, followed by the NS1, M5, M10, and control specimens. Figure $3 \mathrm{~b}$ shows that the shear stress increased when shear rate increased. In the region with a low shear rate of approximately $10 \mathrm{~s}^{-1}$, the shear stress was significantly reduced, probably because of destruction of the flocculated structures due to rotor rotation [48]. The shear stress results are similar to the viscosity values. As the amounts of NS and $\mathrm{MgO}$ increased from $1 \%$ to $2 \%$, the shear stress improved compared to that of the control specimen. However, NS enhanced the viscosity more significantly than $\mathrm{MgO}$. The higher UWC viscosity values could be attributed to the finer particle sizes with higher specific surface areas of $\mathrm{NS}$ and $\mathrm{MgO}$, which required more water to achieve flow [49]. As NS has a much smaller particle size than $\mathrm{MgO}$, its viscosity enhancement effect was greater.

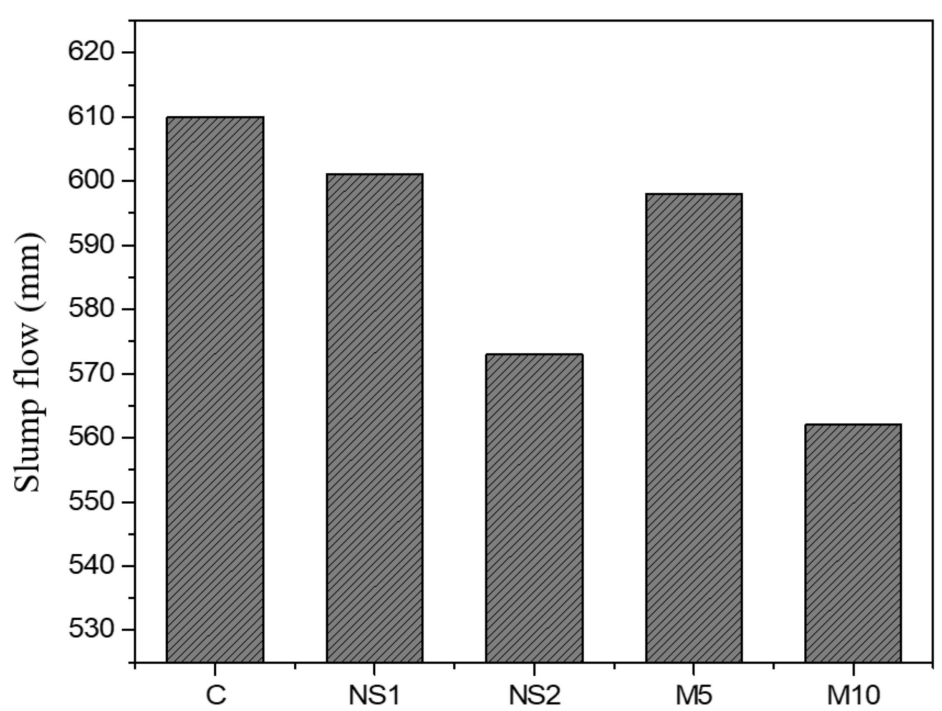

Figure 2. Slump flow results of the underwater concrete (UWC) mixes with different dosages of NS and $\mathrm{MgO}$.

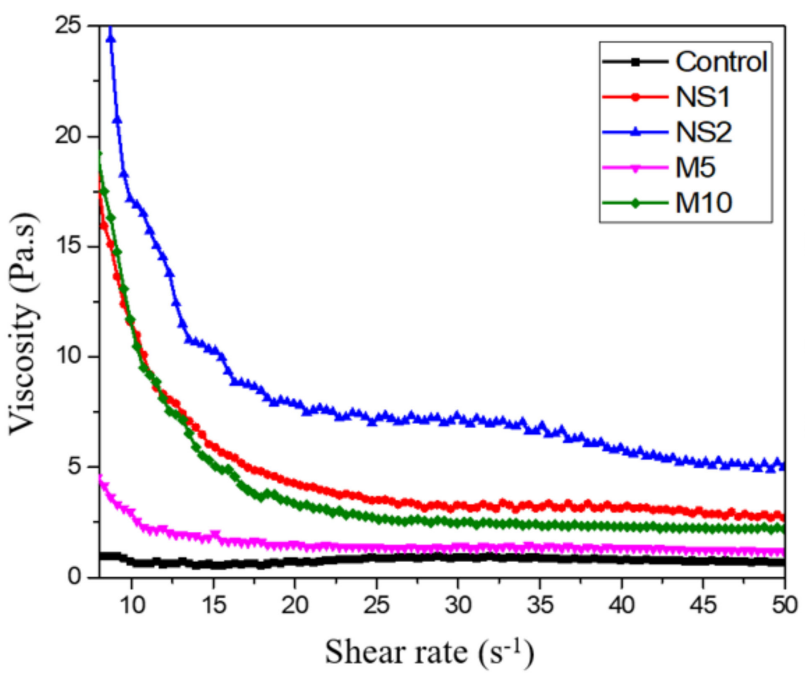

(a)

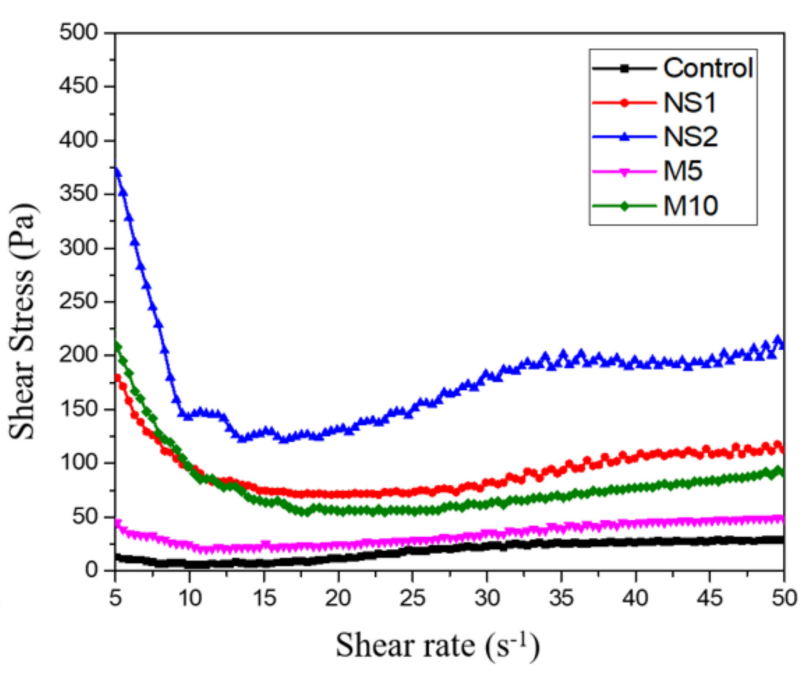

(b)

Figure 3. (a) Viscosity versus shear rate flow curves and (b) shear stress versus shear rate flow curves for UWC paste with different amounts of NS and MgO. 


\subsection{Setting Time}

The initial setting time, the final setting time, and the setting time that is the duration between the initial and final setting times of the UWC pastes with different NS and MgO contents, are illustrated in Figure 4. Both NS and MgO incorporation into the UWC mixes reduced the initial and final setting times compared to the control specimen. When NS was increased from $1 \%$ to $2 \%$ and when $\mathrm{MgO}$ was increased from $5 \%$ to $10 \%$, the initial setting time decreased by $60.1 \%, 79 \%, 38.46 \%$, and $70.63 \%$, respectively, and the final setting time decreased by $42.42 \%, 58.1 \%, 12.1 \%$, and $33.84 \%$ compared to the control specimen. The results showed that the setting time decreased as the NS and $\mathrm{MgO}$ contents increased. However, NS reduced the setting time more significantly than did $\mathrm{MgO}$. The reduction in the setting times of the UWC mixes that contained $\mathrm{NS}$ and $\mathrm{MgO}$ might be related to the finer particle sizes and higher surface areas of $\mathrm{NS}$ and $\mathrm{MgO}$. Zhang et al. [50] found that NS decreased the setting time by reducing the dormant period and enhancing cement hydration. Li et al. [51] reported that the addition of NS promoted the gelation of C$\mathrm{S}-\mathrm{H}$ gels, which reduced their setting time. However, for $\mathrm{MgO}$, the initial setting time decreased, and the setting time improved, compared to that of the control specimen. This was due to the fine particle size and hydration properties of $\mathrm{MgO}$. The finer particle size of $\mathrm{MgO}$ compared to that of OPC gives it a larger surface area and a higher water demand, which shortens the initial setting time. The delay in final setting time could have been due to $\mathrm{Mg}(\mathrm{OH})_{2}$ formation during $\mathrm{MgO}$ hydration. Polat et al. [52] found that $\mathrm{Mg}(\mathrm{OH})_{2}$ formation slowed the hydration process and delayed the setting time by encircling the cement particles.

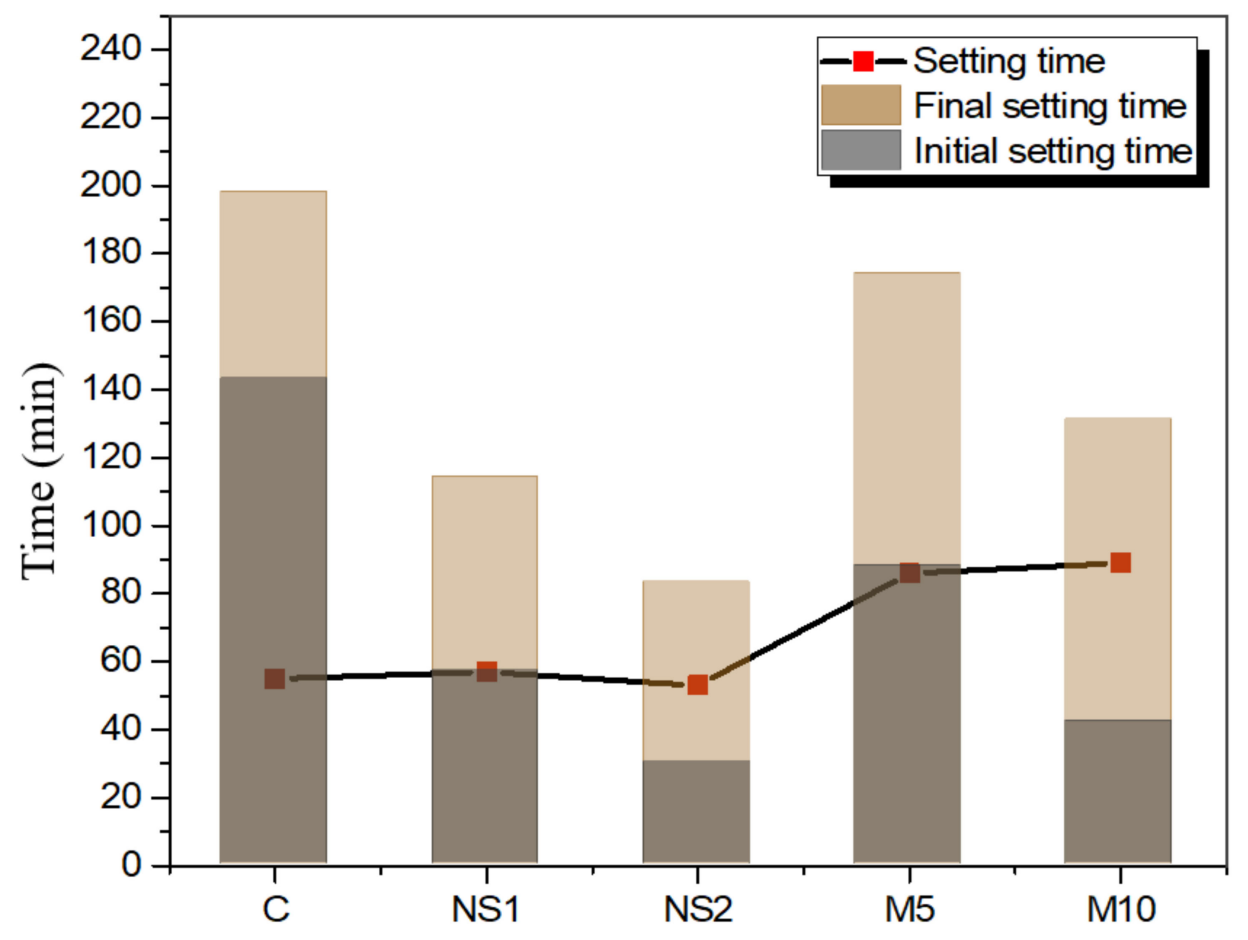

Figure 4. Initial and final setting times of UWC pastes with different amounts of NS and MgO.

\subsection{Anti-Washout Resistance}

To evaluate the anti-washout resistance of the UWC concrete mixes, $\mathrm{pH}$ measurements and a turbidity test were conducted. Figure 5 shows the $\mathrm{pH}$ and turbidity values of each of the mixes. UWC generally loses quality during on-site construction because cement materials are washed off and diluted by water flow [37]. If segregation and washout occur while the concrete mixes are poured, the overall $\mathrm{pH}$ and turbidity of the cement particles with a high $\mathrm{pH}$ value increase in the water. The high $\mathrm{pH}$ and turbidity values of UWC concrete mixes signify their washout resistance ability. As in Figure 5, all the 
mixes showed similar tendencies in terms of $\mathrm{pH}$ and turbidity values. The results indicate that the addition of NS powder reduces the $\mathrm{pH}$ and turbidity values of UWC mixes. For example, $\mathrm{pH}$ values of 11.9, 11.22, and 11.07, and turbidity values of $307.5 \mathrm{NTU}, 192 \mathrm{NTU}$, and 120 NTU, were reported in the control, NS1, and NS2 specimens, respectively. This can be attributed to the reduced segregation of the UWC concrete mixes by the fine particles of NS because of their cohesive effect, as mentioned above. Senff et al. [53] reported that the incorporation of NS can reduce the diameter of the spread on the flow table due to increased cohesiveness. For $\mathrm{MgO}$ replacement, $\mathrm{pH}$ values of 11.9, 11.63, and 11.31 and turbidity values of $307.5 \mathrm{NTU}, 256.5 \mathrm{NTU}$, and $194.5 \mathrm{NTU}$ were measured in the control, M5, and M10 specimens, respectively. The results showed that $\mathrm{pH}$ and turbidity decreased with increased $\mathrm{MgO}$ replacement. The increase in the anti-washout resistance of the UWC that contained $\mathrm{MgO}$ presumably occurred because the fine particles of $\mathrm{MgO}$ increased the cohesion of the concrete mixes. Both NS and MgO increased the cohesion of the UWC mixes due to their finer particle sizes compared to that of OPC, which enhanced the anti-washout resistance of the UWC.

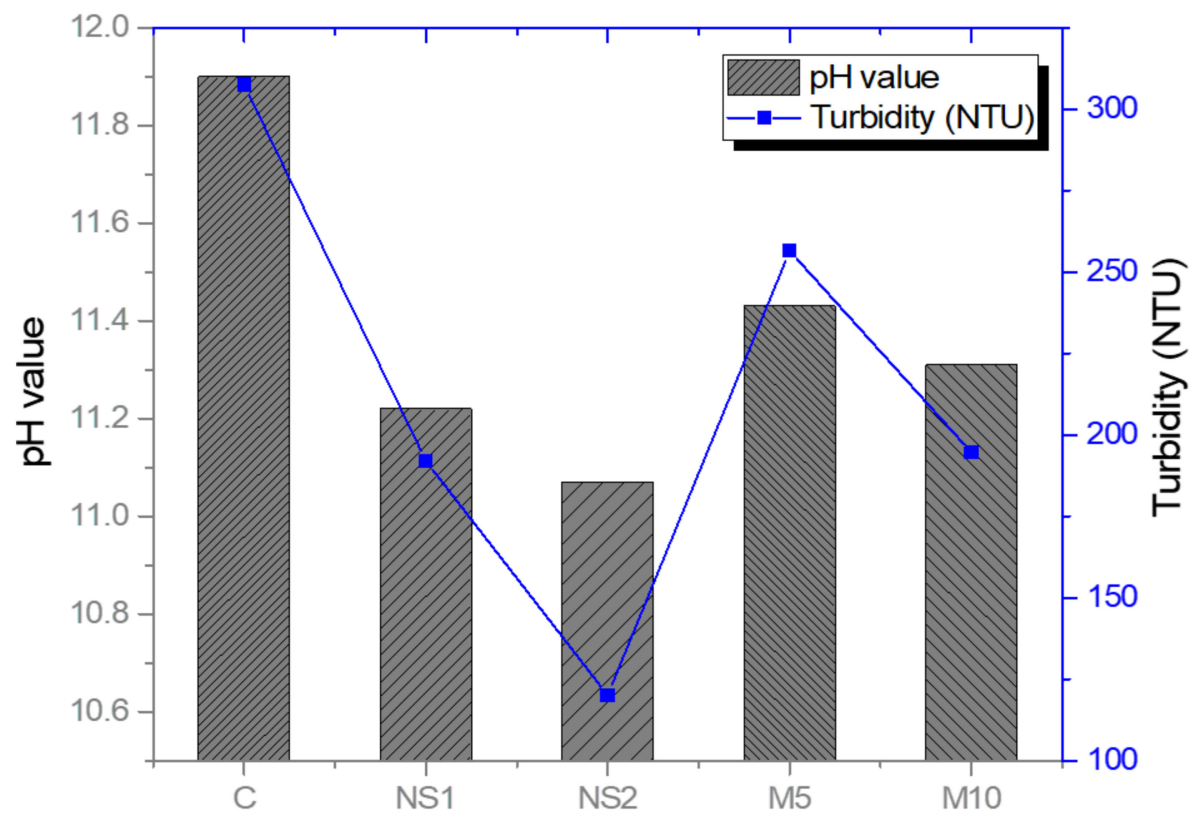

Figure 5. Anti-washout resistance of UWC concrete mixes with NS and $\mathrm{MgO}$.

\subsection{Compressive Strength Test}

To investigate the effects of NS and $\mathrm{MgO}$ on the mechanical properties of the UWC concrete, a compressive strength test was conducted after 7 days and 28 days of curing. The results are shown in Figure 6, whereby the compressive strength increased with curing age in all mixes. This is because the continued hydration of cementitious materials increases the compressive strength. The 28-day compressive strengths attained for C, NS1, NS2, M5, and M10 were $36.73 \mathrm{MPa}, 40.9 \mathrm{MPa}, 41.27 \mathrm{MPa}, 34.11 \mathrm{MPa}$, and $32.88 \mathrm{MPa}$, respectively. After 7 days and 28 days, the compressive strength of the concrete that contained NS was slightly higher than that of the concrete without NS. This strength development with NS was due to the fine particles and high pozzolanic activity of NS, which provide extra nucleation sites to cement particles, accelerate their hydration, and generate additional hydration products. Yu et al. [25] found that the application of nanoparticles can increase the physical and mechanical properties of concrete by refining its microstructure. In addition, Scrivener et al. [54] and $\mathrm{Xu}$ et al. [55] mentioned that nanoparticles can accelerate the hydration process, densify the microstructure, and improve the Interfacial Transition Zone (ITZ) of concrete, which decreases the porosity and enhances the compressive strength of a cement composite. However, the incorporation of $\mathrm{MgO}$ into UWC reduces the compressive 
strength of UWC after 7 days and 28 days, compared to that of the control specimen. As the $\mathrm{MgO}$ proportion increased from $0 \%$ to $10 \%$, the compressive strength of M5 and M10 decreased by $7.13 \%$ and $10.48 \%$, respectively, after 28 days of curing, compared to the control specimen. This is because the amorphous active silica in $\mathrm{MgO}$ can react with $\mathrm{MgO}$ or $\mathrm{Mg}(\mathrm{OH})_{2}$ and water during the hydration process [56,57]. Unluer et al. [58] reported that $\mathrm{MgO}$ reduced the compressive strength of cement due to the formation of brucite, which is weaker than $\mathrm{C}-\mathrm{S}-\mathrm{H}$, in normal cement hydration.

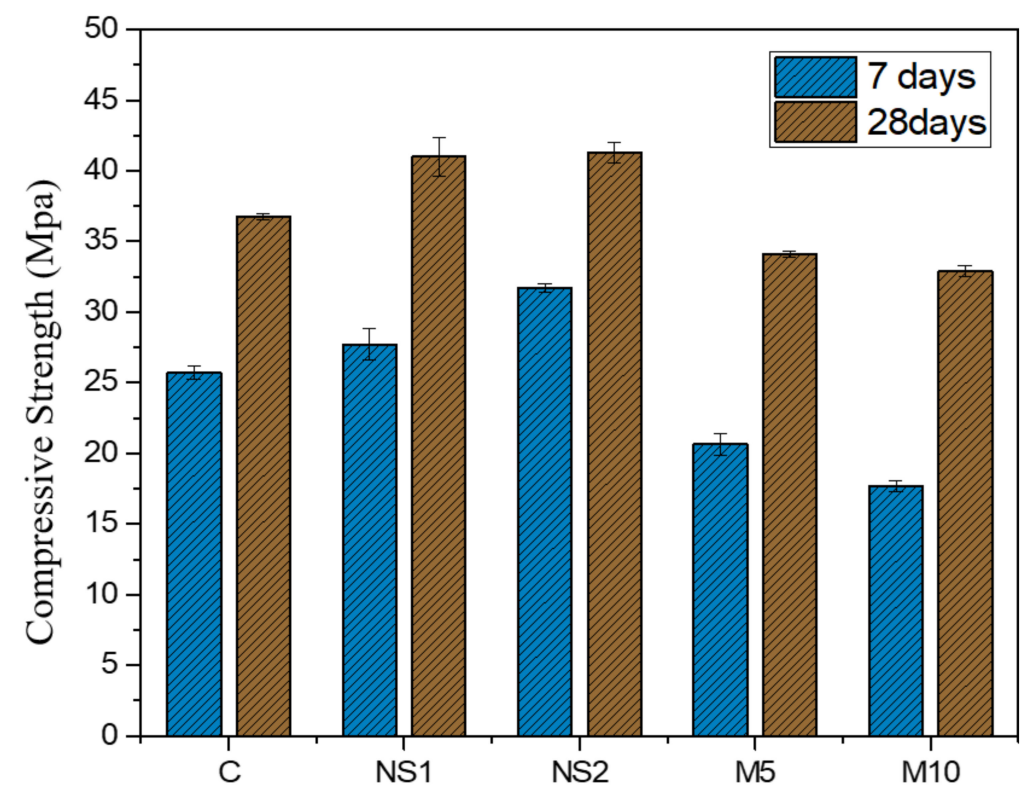

Figure 6. Compressive strength results of UWC concrete specimens with different amounts of NS and $\mathrm{MgO}$ after 7- and 28-day curing.

\subsection{Hydration Heat}

The isothermal calorimetry method is used to investigate the effects of temperature on the reaction kinetics of cementitious materials [40]. Figure 7 shows the calorimetric curves of heat release from the UWC specimens with (a) NS and (b) MgO. Detailed information on peak time and peak temperature variation is listed in Table 2.

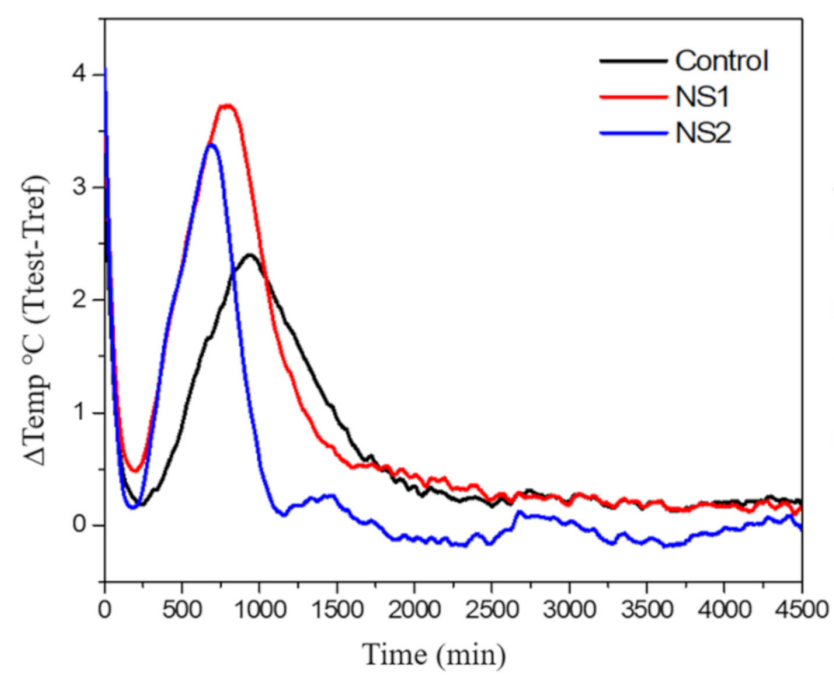

(a)

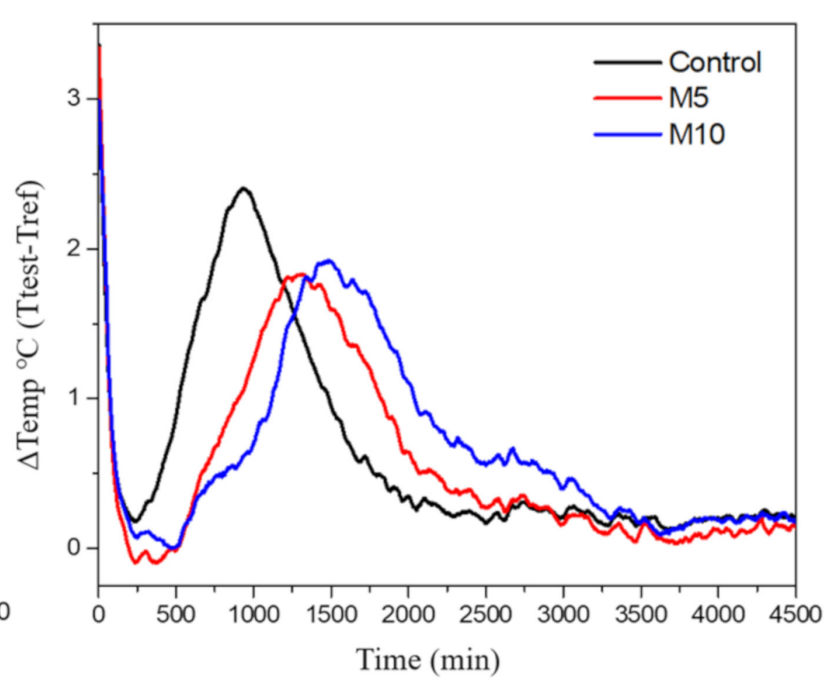

(b)

Figure 7. Calorimetric curves of the rate of heat release of (a) UWC with different NS contents and (b) UWC with different amounts of $\mathrm{MgO}$. 
Table 2. Isothermal details of the UWC specimens with NS and $\mathrm{MgO}$.

\begin{tabular}{ccc}
\hline Concrete Mix & Peak Time (min) & Peak Temperature $\left(\boldsymbol{\Delta}^{\circ} \mathbf{C}\right)$ \\
\hline Control & 940 & 2.40 \\
NS1 & 784 & 3.73 \\
NS2 & 696 & 3.38 \\
M5 & 1222 & 1.81 \\
M10 & 1492 & 1.92 \\
\hline
\end{tabular}

The first sharp peak was produced from the dissolution of the dry mixtures, and occurred immediately after the mixtures were mixed [59]. The second peak was generated between 500 and $2000 \mathrm{~min}$ and was related to the polymerization degree of the binder materials [60]. Figure 7a shows that the incorporation of NS into the UWC specimens accelerated the peak time and increased the peak temperature variation. Peak times of $940 \mathrm{~min}, 784 \mathrm{~min}$, and $696 \mathrm{~min}$ were reported for the control, NS1, and NS2 specimens, respectively. In addition, the control, NS1, and NS2 specimens showed temperature variations of $2.4{ }^{\circ} \mathrm{C}, 3.73{ }^{\circ} \mathrm{C}$, and $3.38{ }^{\circ} \mathrm{C}$, respectively. This effect was mainly due to the seeding effect of nano-materials. Moreover, the acceleration effect of NS particles on cement hydration was due to the additional nucleation of $\mathrm{C}-\mathrm{S}-\mathrm{H}$ caused by the increased surface area of the nano-particles [61,62]. However, NS1 showed higher temperature variation compared to NS2. This phenomenon might be due to the dispersion of NS particles in the cement composite. The usage of more than adequate amounts of NS is considered to reduce efficiency due to the dispersion problem [63]. Figure $7 \mathrm{~b}$ shows the effect of $\mathrm{MgO}$ content on the heat release of UWC specimens. When the amount of $\mathrm{MgO}$ increased, the peak time tended to be delayed, and the peak temperature was lower than that of the specimens without $\mathrm{MgO}$. Although $\mathrm{MgO}$ has a smaller particle size than OPC, the UWC specimens that contained $\mathrm{MgO}$ showed lower hydration rates and heat release due to the lower reactivity of $\mathrm{MgO}$. Mehta et al. [64] reported that the $\mathrm{MgO}$ within cement slightly delayed hydration by producing magnesium hydroxide, which is insoluble.

\subsection{Thermogravimetric Analysis}

Figure 8 shows the Derivative Thermo Gravimetry (DTG) curves of the UWC mixes with different amounts of NS and MgO after 28 days of curing. All the UWC mixes showed mass loss peaks in four temperature regions. The mass loss below $15^{\circ} \mathrm{C}$ is attributed to the evaporation of free water from the pore structure [65,66]. Lothenbach et al. [67] found that mass losses between 50 and $200{ }^{\circ} \mathrm{C}$ were caused by the dehydration of $\mathrm{C}-\mathrm{S}-\mathrm{H}$, and the secondary peaks at around $146{ }^{\circ} \mathrm{C}$ were associated with the decomposition of ettringite. Bernal et al. [68] and Rozov et al. [69] reported that the mass losses between 250 and $400{ }^{\circ} \mathrm{C}$ were related to the thermal decomposition of hydrotalcite. In the present study, no carbonate source was used, so the mass loss in this region was mainly due to the dehydroxylation of hydrotalcite [70]. In addition, the $\mathrm{C}-\mathrm{H}$ groups at around $420{ }^{\circ} \mathrm{C}$ and between 660 and $700{ }^{\circ} \mathrm{C}$ were associated with the decarbonation of $\mathrm{CaCO}_{3}$. However, this carbonate region can be generated through powder manufacturing [71]. The results showed that increasing the NS content increased the mass loss when below $200{ }^{\circ} \mathrm{C}$, as seen on the DTG curve of the UWC mixes. For specimens with and without NS, the type of hydration products remained unchanged. Only M5 and M10, which contained MgO, showed significant mass losses between 250 and $400{ }^{\circ} \mathrm{C}$, which indicated the presence of hydrotalcite in the UWC with $\mathrm{MgO}$. 


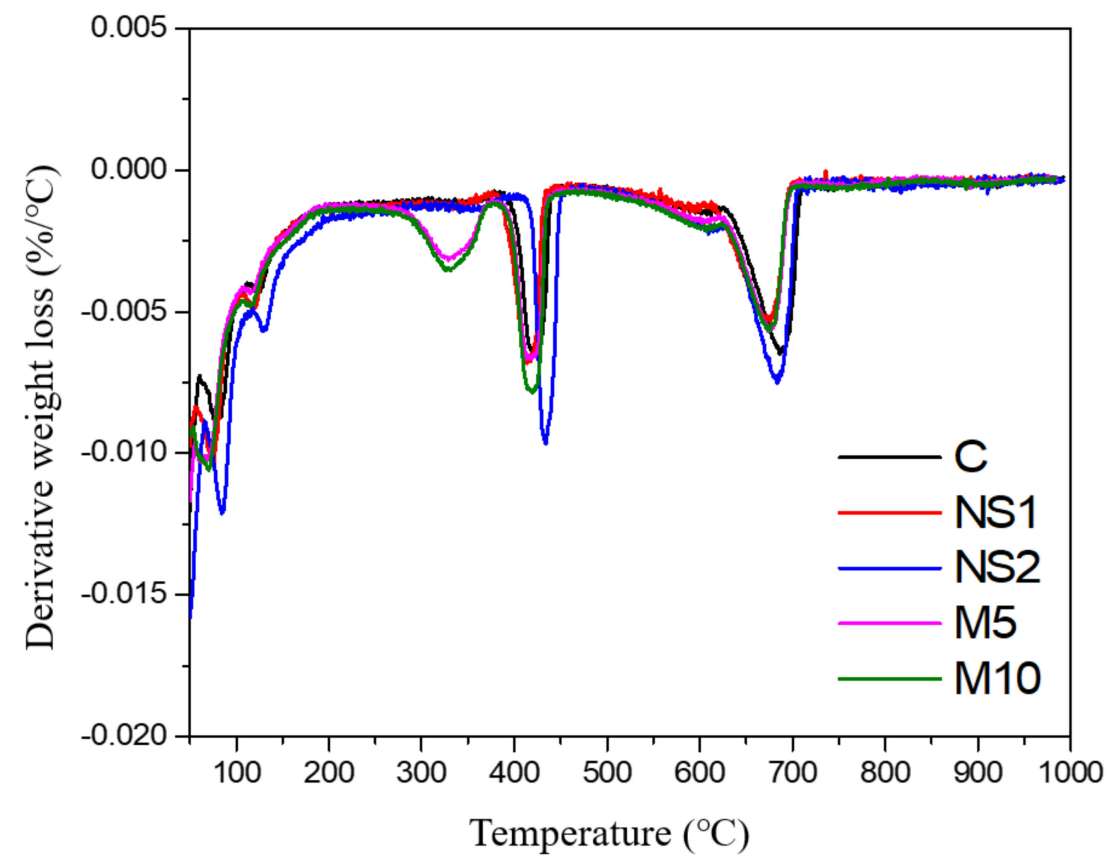

Figure 8. DTG curves of the UWC mixes with different amounts of NS and MgO.

Figure 9 shows that the mass loss fractions contributed to the C-S-H $\left(50-200{ }^{\circ} \mathrm{C}\right)$ and the hydrotalcite $\left(250-400^{\circ} \mathrm{C}\right)$ of the UWC mixtures as functions of NS and $\mathrm{MgO}$. In the 50 to $200{ }^{\circ} \mathrm{C}$ region, the specimens that contained NS had higher mass loss than the control specimens. For example, mass loss fractions of $8.4 \%, 8.9 \%$, and $10.3 \%$ were noted in the control, NS1, and NS2 specimens, respectively. The increase in the C-S-H gel is attributed to the promotion of cement hydration by NS due to its pozzolanic activity and nucleation effect [72]. In addition, in the 250 to $400{ }^{\circ} \mathrm{C}$ region, the specimens that contained $\mathrm{MgO}$ showed enhanced mass loss fractions, which led to higher amounts of hydrotalcite. A similar phenomenon was reported in a previous study. Yoon et al. [73] found that, when $\mathrm{MgO}$ was incorporated in a cement composite, the $\mathrm{MgO}$ combined with $\mathrm{Al}$ and promoted the generation of the hydrotalcite phase in the cement composite.

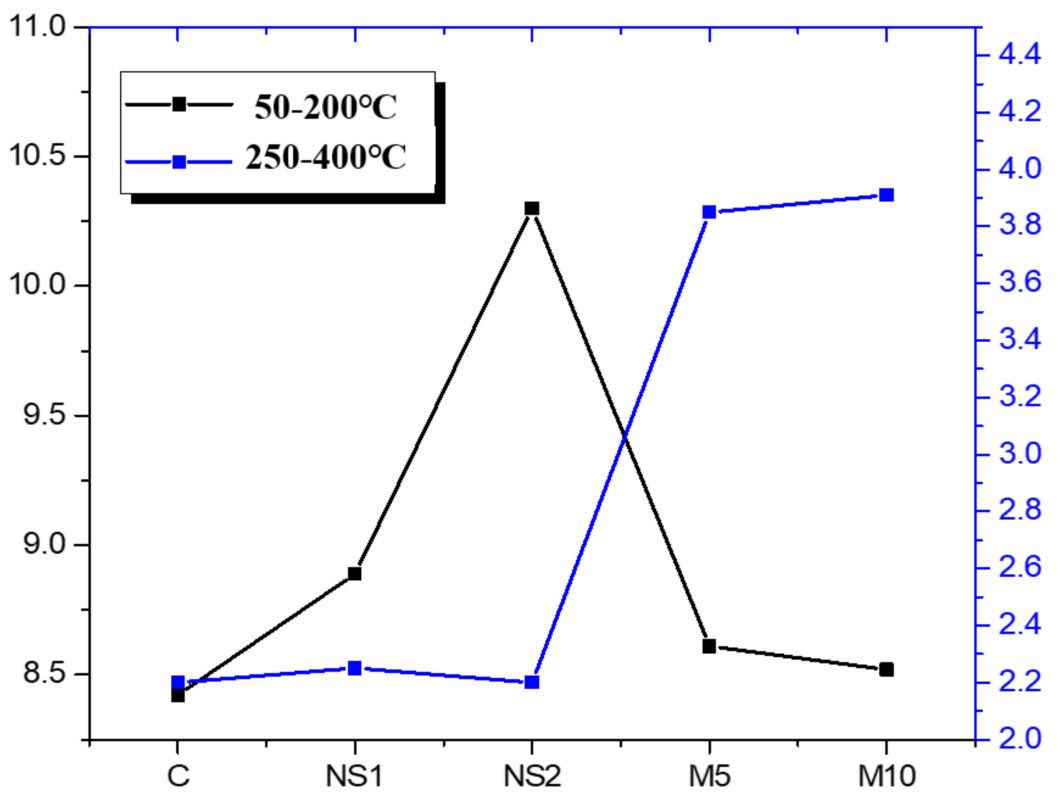

Figure 9. Mass loss fractions at different temperature ranges of the UWC mixes as a function of NS and $\mathrm{MgO}$. 


\section{Conclusions}

This study investigated the effects of NS and $\mathrm{MgO}$ on the hydration characteristics and anti-washout resistance of non-dispersible UWC concrete. The following conclusions were reached.

1. The results of the rheological experiments revealed that the fine particles and large specific areas of NS and $\mathrm{MgO}$ reduced the flowability and increased the viscosity of UWC. However, the impact of the smaller NS on the rheological properties was greater than that of $\mathrm{MgO}$;

2. Both $\mathrm{NS}$ and $\mathrm{MgO}$ shortened the initial and final setting times compared to the control specimens due to their fine particle sizes. However, $\mathrm{MgO}$ prolonged the setting time (the duration between the initial and final setting times) due to the formation of an insoluble hydration product. The hydration heat analysis showed that NS accelerated the hydration process and increased the hydration heat, whereas $\mathrm{MgO}$ delayed the peak time and reduced the temperature;

3. The anti-washout performance results showed similar $\mathrm{pH}$ and turbidity tendencies in all the mixes. Both the addition of NS and replacement OPC with $\mathrm{MgO}$ reduced the $\mathrm{pH}$ and turbidity values, demonstrating that both $\mathrm{NS}$ and $\mathrm{MgO}$ increased the cohesion of the UWC mixes due to their finer particle size compared to that of OPC, which enhanced the anti-washout resistance of the UWC;

4. The addition of NS slightly increased the compressive strength of the UWC because the high pozzolanic activity of NS generated extra nucleation sites and accelerated the hydration process. However, $\mathrm{MgO}$ decreased the compressive strength of $\mathrm{M} 5$ and M10 by $7.13 \%$ and $10.48 \%$, respectively, compared to that of the control specimen due to the formation of brucite;

5. The TGA results showed that NS promoted the generation of $\mathrm{C}-\mathrm{S}-\mathrm{H}$ gel due to its pozzolanic activity and nucleation effect. In addition, the specimens that contained $\mathrm{MgO}$ showed enhanced mass loss fractions at 25 to $400{ }^{\circ} \mathrm{C}$, which generated larger amounts of hydrotalcite.

Author Contributions: Data curation, I.K.J.; Formal analysis, I.K.J.; Funding acquisition, J.S.R.; Investigation, I.K.J., B.H.W., D.H.Y. and H.G.K.; Methodology, B.H.W.; Project administration, I.K.J. and J.S.R.; Supervision, H.G.K.; Visualization, D.H.Y.; Writing—original draft, I.K.J.; Writing-review \& editing, I.K.J. All authors have read and agreed to the published version of the manuscript.

Funding: This research was supported by Basic Science Research Program through the National Research Foundation of Korea (NRF) funded by the Ministry of Education(2019R1I1A2A01064072).

Institutional Review Board Statement: Not applicable.

Informed Consent Statement: Not applicable.

Data Availability Statement: Data sharing is not applicable.

Acknowledgments: This research was supported by the Basic Science Research Program through the National Research Foundation of Korea (NRF) funded by the Ministry of Education (2019R1I1A2A01064072).

Conflicts of Interest: The authors declare no conflict of interest.

\section{References}

1. Ren, W.; Sneed, L.H.; Gai, Y.; Kang, X. Test results and nonlinear analysis of RC T-beams strengthened by bonded steel plates. Int. J. Concr. Struct. Mater. 2015, 9, 133-143. [CrossRef]

2. Lehman, D.E.; Gookin, S.E.; Nacamuli, A.M.; Moehle, J.P. Repair of earthquake-damaged bridge columns. Struct. J. 2001, 98, 233-242.

3. Parghi, A.; Alam, M.S. Seismic behavior of deficient reinforced concrete bridge piers confined with FRP-A fractional factorial analysis. Eng. Struct. 2016, 126, 531-546. [CrossRef]

4. Saeed, H.Z.; Ahmed, A.; Ali, S.M.; Iqbal, M. Experimental and finite element investigation of strengthened LSC bridge piers under Quasi-Static Cyclic Load Test. Comp. Struct. 2015, 131, 556-564. [CrossRef] 
5. Jun, A.; Liyuan, S. Discussion of design and construction method on extraneous prestressed strengthening technique for bridge. J. Southeast Univ. 2002, 32, 771-7741.

6. Zhu, J.-H.; Su, M.-H.; Huang, J.-Y.; Ueda, T.; Xing, F. The ICCP-SS technique for retrofitting reinforced concrete compressive members subjected to corrosion. Construct. Build. Mater. 2018, 167, 669-679. [CrossRef]

7. Yi, N.H.; Nam, J.W.; Kim, S.B.; Kim, I.S.; Kim, J.-H.J. Evaluation of material and structural performances of developed AquaAdvanced-FRP for retrofitting of underwater concrete structural members. Construct. Build. Mater. 2010, 24, 566-576. [CrossRef]

8. Menkulasi, F.; Baghi, H.; Hall, D.; Farzana, N. Rehabilitation of Deteriorated Timber Piles with Fiber Reinforced Polymer Composites. In Proceedings of the IABSE Symposium Report, Nantes, France, 19-21 September 2018; pp. 381-388.

9. Wei, Y.; Wu, G.; Wu, Z. Several innovative strengthening technologies for underwater piers. Build. Struct. 2010, 40, 683-686.

10. Yamaguchi, M.; Tsuchida, T. Development of high-viscosity underwater concrete for marine structures. Marine Concrete. In Proceedings of the International Conference on Concrete in the Marine Environment, Concrete Society, London, UK, 22-24 September 1986; pp. 235-245.

11. Han, B.; Zhang, L.; Ou, J. Non-Dispersible Underwater Concrete. In Smart and Multifunctional Concrete Toward Sustainable InfraStructures; Springer: Berlin/Heidelberg, Germany, 2017; pp. 369-377.

12. Khayat, K.H. Effects of antiwashout admixtures on fresh concrete properties. Mater. J. 1995, 92, $164-171$.

13. Heniegal, A.M.; Maaty, A.A.E.S.; Agwa, I.S. Simulation of the behavior of pressurized underwater concrete. Alexand. Eng. J. 2015, 54, 183-195. [CrossRef]

14. Park, J.-J.; Moon, J.-H. An Estimation on the Performance of High Fluidity Anti-washout Underwater Concrete. Adv. Mater. Res. 2014, 577-578, 501-504. [CrossRef]

15. Kumar, V.; Kumar, R.; Mandal, S.; Sinha, A. Admixtures for underwater concreteing for repair of cracks in the structure. In Proceedings of the 30th Conference on Our World in Concrete \& Structures, Singapore, 29-30 August 2002.

16. Khayat, K.H.; Sonebi, M. Effect of mixture composition on washout resistance of highly flowable underwater concrete. Mater. J. 2001, 98, 289-295.

17. Grzeszczyk, S.; Jurowski, K.; Bosowska, K.; Grzymek, M. The role of nanoparticles in decreased washout of underwater concrete. Construct. Build. Mater. 2019, 203, 670-678. [CrossRef]

18. Sonebi, M.; Khayat, K. Effect of mixture composition on relative strength of highly flowable underwater concrete. Mater. J. 2001, 98, 233-239.

19. Kojouri, S.J.; Abang Ali, A.A.; Farzadnia, N. Effect of Colloidal Nano Silica as a Viscosity Modifying Agent in Self Compacting Concrete with High Volume POFA. Adv. Mater. Res. 2016, 1133, 491-495. [CrossRef]

20. Meng, T.; Hong, Y.; Wei, H.; Xu, Q. Effect of nano-SiO2 with different particle size on the hydration kinetics of cement. Thermochim. Acta 2019, 675, 127-133. [CrossRef]

21. Kumar, S.; Ali, N.; Begum, S.; Rahman, Z. Characterization, properties and microstructure studies of cement mortar incorporating nano-SiO2. Mater. Today Proceed. 2020, 37, 425-430. [CrossRef]

22. Zhou, J.; Zheng, K.; Liu, Z.; He, F. Chemical effect of nano-alumina on early-age hydration of Portland cement. Cem. Concr. Res. 2019, 116, 159-167. [CrossRef]

23. Berra, M.; Carassiti, F.; Mangialardi, T.; Paolini, A.; Sebastiani, M. Effects of nanosilica addition on workability and compressive strength of Portland cement pastes. Construct. Build. Mater. 2012, 35, 666-675. [CrossRef]

24. Nazari, A.; Riahi, S. The effects of $\mathrm{SiO} 2$ nanoparticles on physical and mechanical properties of high strength compacting concrete. Compos. Part B Eng. 2011, 42, 570-578. [CrossRef]

25. Yu, R.; Spiesz, P.; Brouwers, H. Effect of nano-silica on the hydration and microstructure development of Ultra-High Performance Concrete (UHPC) with a low binder amount. Construct. Build. Mater. 2014, 65, 140-150. [CrossRef]

26. Yeşilmen, S.; Al-Najjar, Y.; Balav, M.H.; Şahmaran, M.; Yıldırım, G.; Lachemi, M. Nano-modification to improve the ductility of cementitious composites. Cem. Concr. Res. 2015, 76, 170-179. [CrossRef]

27. Behfarnia, K.; Salemi, N. The effects of nano-silica and nano-alumina on frost resistance of normal concrete. Construct. Build. Mater. 2013, 48, 580-584. [CrossRef]

28. Madani, H.; Bagheri, A.; Parhizkar, T.; Raisghasemi, A. Chloride penetration and electrical resistivity of concretes containing nanosilica hydrosols with different specific surface areas. Cem. Concr. Compos. 2014, 53, 18-24. [CrossRef]

29. Lingling, X.; Min, D. Dolomite used as raw material to produce MgO-based expansive agent. Cem. Concr. Res. 2005, 35, 1480-1485. [CrossRef]

30. Jang, B.-S.; Kwon, Y.-G.; Choi, S.-W.; Lee, K.-M. Fundamental properties of cement composites containing lightly burnt MgO powders. J. Korea Concr. Inst. 2011, 23, 225-233. [CrossRef]

31. Mo, L.; Deng, M.; Tang, M. Potential approach to evaluating soundness of concrete containing MgO-based expansive agent. ACI Mater. J. 2010, 107, 99.

32. Gao, P.-w.; Wu, S.-x.; Lin, P.-h.; Wu, Z.-r.; Tang, M.-s. The characteristics of air void and frost resistance of RCC with fly ash and expansive agent. Construct. Build. Mater. 2006, 20, 586-590. [CrossRef]

33. Yousri, K. Self-flowing underwater concrete mixtures. Mag. Concr. Res. 2008, 60, 1-10. [CrossRef]

34. Yao, S.X.; Berner, D.E.; Gerwick, B.C. Assessment of Underwater Concrete Technologies for in-the-Wet Construction of Navigation Structures; GERWICK (BEN C) INC: San Francisco, CA, USA, 1999. 
35. American Society for Testing and Materials. C150/C150M-17, Standard Specification for Portland Cement; American Society for Testing and Materials: West Conshohocken, PA, USA, 2017.

36. Specimens, C.T. ASTM C 31/C 31M. a. Cast and Laboratory Cure Two Sets of Two Standard Cylinder Specimens for Each Composite Sample. b. Cast and Field Cure Two Sets of Two Standard Cylinder Specimens for Each Composite Sample; American Society for Testing and Materials: West Conshohocken, PA, USA, 2019.

37. Moon, H.Y.; Shin, K.J. Evaluation on steel bar corrosion embedded in antiwashout underwater concrete containing mineral admixtures. Cem. Concr. Res. 2006, 36, 521-529. [CrossRef]

38. Standard, A. C143, 2010. Standard Test Method for Slump of Hydraulic-Cement Concrete; ASTM International: West Conshohocken, PA, USA, 2012.

39. Ding, Z.; Li, H.; Wei, J.; Li, R.; Yan, Y. Developing a novel magnesium glycerophosphate/silicate-based organic-inorganic composite cement for bone repair. Mater. Sci. Eng. C 2018, 87, 104-111. [CrossRef]

40. Jeon, I.K.; Ryou, J.S.; Jakhrani, S.H.; Kim, H.G. Effects of Light-Burnt Dolomite Incorporation on the Setting, Strength, and Drying Shrinkage of One-Part Alkali-Activated Slag Cement. Materials 2019, 12, 2874. [CrossRef] [PubMed]

41. American Society for Testing and Materials. 191. Standard Test Method for Time of Setting of Hydraulic Cement by Vicat Needle; American Society for Testing and Materials: West Conshohocken, PA, USA, 2006.

42. Sikandar, M.A.; Wazir, N.R.; Khan, M.A.; Nasir, H.; Ahmad, W.; Alam, M. Effect of various anti-washout admixtures on the properties of non-dispersible underwater concrete. Construct. Build. Mater. 2020, 245, 118469. [CrossRef]

43. ISO. International Standards ISO 7027-Water Quality—Determination of Turbidity; International Organization for Standards: Geneva, Switzerland, 1990.

44. American Society for Testing and Materials. ASTM C39/C39M-12 Standard Test Method for Compressive Strength of Cylindrical Concrete Specimens; American Society for Testing and Materials: West Conshohocken, PA, USA, 2012.

45. Moon, H.; Ramanathan, S.; Suraneni, P.; Shon, C.-S.; Lee, C.-J.; Chung, C.-W. Revisiting the effect of slag in reducing heat of hydration in concrete in comparison to other supplementary cementitious materials. Materials 2018, 11, 1847. [CrossRef]

46. Quercia, G.; Hüsken, G.; Brouwers, H. Water demand of amorphous nano silica and its impact on the workability of cement paste. Cem. Concr. Res. 2012, 42, 344-357. [CrossRef]

47. Zhang, R.; Panesar, D.K. New approach to calculate water film thickness and the correlation to the rheology of mortar and concrete containing reactive MgO. Construct. Build. Mater. 2017, 150, 892-902. [CrossRef]

48. Cheng, B.; Yao, C.; Xiong, J.; Liu, X.; Zhang, H.; Zhang, S. Effects of Sodium Hexametaphosphate Addition on the Dispersion and Hydration of Pure Calcium Aluminate Cement. Materials 2020, 13, 5229. [CrossRef]

49. Chougan, M.; Ghaffar, S.H.; Jahanzat, M.; Albar, A.; Mujaddedi, N.; Swash, R. The influence of nano-additives in strengthening mechanical performance of 3D printed multi-binder geopolymer composites. Construct. Build. Mater. 2020, 250, 118928. [CrossRef]

50. Zhang, M.-H.; Islam, J. Use of nano-silica to reduce setting time and increase early strength of concretes with high volumes of fly ash or slag. Construct. Build. Mater. 2012, 29, 573-580. [CrossRef]

51. Li, W.; Shaikh, F.U.; Wang, L.; Lu, Y.; Wang, B.; Jiang, C.; Su, Y. Experimental study on shear property and rheological characteristic of superfine cement grouts with nano-SiO2 addition. Construct. Build. Mater. 2019, 228, 117046. [CrossRef]

52. Polat, R.; Demirboğa, R.; Karagöl, F. The effect of nano-MgO on the setting time, autogenous shrinkage, microstructure and mechanical properties of high performance cement paste and mortar. Construct. Build. Mater. 2017, 156, 208-218. [CrossRef]

53. Senff, L.; Labrincha, J.A.; Ferreira, V.M.; Hotza, D.; Repette, W.L. Effect of nano-silica on rheology and fresh properties of cement pastes and mortars. Construct. Build. Mater. 2009, 23, 2487-2491. [CrossRef]

54. Scrivener, K.L.; Kirkpatrick, R.J. Innovation in use and research on cementitious material. Cem. Concr. Res. 2008, 38, 128-136. [CrossRef]

55. Xu, J.; Wang, B.; Zuo, J. Modification effects of nanosilica on the interfacial transition zone in concrete: A multiscale approach Cem. Concr. Compos. 2017, 81, 1-10. [CrossRef]

56. Bernard, E.; Lothenbach, B.; Chlique, C.; Wyrzykowski, M.; Dauzeres, A.; Pochard, I.; Cau-Dit-Coumes, C. Characterization of magnesium silicate hydrate (MSH). Cem. Concr. Res. 2019, 116, 309-330. [CrossRef]

57. Bernard, E.; Lothenbach, B.; Rentsch, D.; Pochard, I.; Dauzères, A. Formation of magnesium silicate hydrates (MSH). Phys. Chem. Earth Parts A B C 2017, 99, 142-157. [CrossRef]

58. Unluer, C. Carbon dioxide sequestration in magnesium-based binders. In Carbon Dioxide Sequestration in Cementitious Construction Materials; Elsevier: Amsterdam, The Netherlands, 2018; pp. 129-173.

59. Bernal, S.A.; de Gutierrez, R.M.; Provis, J.L.; Rose, V. Effect of silicate modulus and metakaolin incorporation on the carbonation of alkali silicate-activated slags. Cem. Concr. Res. 2010, 40, 898-907. [CrossRef]

60. Zhang, Z.; Wang, H.; Provis, J.L.; Bullen, F.; Reid, A.; Zhu, Y. Quantitative kinetic and structural analysis of geopolymers. Part 1. The activation of metakaolin with sodium hydroxide. Thermochim. Acta 2012, 539, 23-33. [CrossRef]

61. Thomas, J.J.; Jennings, H.M.; Chen, J.J. Influence of nucleation seeding on the hydration mechanisms of tricalcium silicate and cement. J. Phys. Chem. C 2009, 113, 4327-4334. [CrossRef]

62. Gu, Y.; Ran, Q.; Shu, X.; Yu, C.; Chang, H.; Liu, J. Synthesis of nanoSiO2@ PCE core-shell nanoparticles and its effect on cement hydration at early age. Construct. Build. Mater. 2016, 114, 673-680. [CrossRef]

63. Feng, P.; Chang, H.; Liu, X.; Ye, S.; Shu, X.; Ran, Q. The significance of dispersion of nano-SiO2 on early age hydration of cement pastes. Mater. Design 2020, 186, 108320. [CrossRef] 
64. Mehta, P.K.; Monteiro, P.J. Concrete Microstructure, Properties and Materials; McGraw-Hill Education: New York, NY, USA, 2017.

65. Duxson, P.; Lukey, G.C.; van Deventer, J.S. Physical evolution of Na-geopolymer derived from metakaolin up to $1000{ }^{\circ} \mathrm{C}$. J. Mater. Sci. 2007, 42, 3044-3054. [CrossRef]

66. Rivera, O.; Long, W.; Weiss, C., Jr.; Moser, R.; Williams, B.; Torres-Cancel, K.; Gore, E.; Allison, P. Effect of elevated temperature on alkali-activated geopolymeric binders compared to portland cement-based binders. Cem. Concr. Res. 2016, 90, 43-51. [CrossRef]

67. Lothenbach, B.; Le Saout, G.; Gallucci, E.; Scrivener, K. Influence of limestone on the hydration of Portland cements. Cem. Concr. Res. 2008, 38, 848-860. [CrossRef]

68. Bernal, S.A.; Provis, J.L.; Walkley, B.; San Nicolas, R.; Gehman, J.D.; Brice, D.G.; Kilcullen, A.R.; Duxson, P.; van Deventer, J.S. Gel nanostructure in alkali-activated binders based on slag and fly ash, and effects of accelerated carbonation. Cem. Concr. Res. 2013, 53, 127-144. [CrossRef]

69. Rozov, K.; Berner, U.; Taviot-Gueho, C.; Leroux, F.; Renaudin, G.; Kulik, D.; Diamond, L.W. Synthesis and characterization of the LDH hydrotalcite-pyroaurite solid-solution series. Cem. Concr. Res. 2010, 40, 1248-1254. [CrossRef]

70. Myers, R.J.; Lothenbach, B.; Bernal, S.A.; Provis, J.L. Thermodynamic modelling of alkali-activated slag cements. Appl. Geochem. 2015, 61, 233-247. [CrossRef]

71. Jeon, I.K.; Qudoos, A.; Jakhrani, S.H.; Kim, H.G.; Ryou, J.-S. Investigation of sulfuric acid attack upon cement mortars containing silicon carbide powder. Powder Technol. 2020, 359, 181-189. [CrossRef]

72. Zhang, B.; Tan, H.; Shen, W.; Xu, G.; Ma, B.; Ji, X. Nano-silica and silica fume modified cement mortar used as Surface Protection Material to enhance the impermeability. Cem. Concr. Compos. 2018, 92, 7-17. [CrossRef]

73. Yoon, H.; Park, S.M.; Lee, H.-K. Effect of MgO on chloride penetration resistance of alkali-activated binder. Construct. Build. Mater. 2018, 178, 584-592. [CrossRef] 